\title{
SOBRE O ENSAIO “A OBRA DE ARTE NA ERA DE SUA REPRODUTIBILIDADE TÉCNICA"
}

Fabrícia de Castro Abreu

\section{RESUMO}

No ensaio $A$ obra de arte na era de sua reprodutibilidade técnica, Benjamin reflete sobre como os meios técnicos de reprodução denegriram a "aura" da obra de arte, fazendo com que esta viesse a perder sua "singularidade", "autenticidade" e "unicidade", ou seja, seu hic et nunc, e com essa função alterada, estaria apta a recepcionar o valor de exposição, ligado à massa, ao grande público, pela sua própria capacidade de reproduzir-se tecnicamente, e desta forma pronta a cumprir uma função política, só possível através da substituição do seu valor de culto (Kultwert) pelo valor de exposição (Ausstellungswert).

Palavras-chave: Arte. Obra. Reprodutibilidade. Técnica. Benjamin.

\section{ABOUT THE ESSAY "THE WORK OF ART IN THE AGE OF MECHANICAL REPRODUCTION"}

\begin{abstract}
The essay "The work of art in the age of mechanical reproduction", Benjamin reflects on how the tecnical means of reproduction denegrated the "aura" of work of art, making this come to lose is "uniqueness", "authenticity" and "uniqueness", ie its hic et nunc, and this exposure value, earthed to the general public, by his oun ability to play technically, and this ready way to comply with a political function, oly possible by replacing its cult value (Kultwert) the exposure value (Ausstellungswert).
\end{abstract}

Keywords: Art. Work. Reproducibility. Technical. Benjamin. 
Para iniciarmos nossas considerações é interessante perceber primeiramente o contexto no qual Walter Benjamin ${ }^{1}$ foi influenciado a analisar a cultura e a arte. $O$ período entre o fim do século XIX e o início da Primeira Guerra Mundial trouxe significativas mudanças no tocante a estilos de vida e formas de pensar. Uma dessas mudanças ficou conhecida como Belle Époque, donde, através de uma paz instaurada juntamente com o avanço tecnológico e econômico, foi surgindo um estilo de ostentação do luxo e desenvolvimento de uma cultura burguesa. As diversas revoluções do século XIX contribuíram para que os dirigentes políticos, influenciados pelo temor do surgimento de mais processos revolucionários, passassem a desenvolver práticas socais nos âmbitos do trabalho, da educação e da segurança, visando conter a agitação da classe trabalhadora.

Com o índice de analfabetismo baixo e a situação econômica favorável, causados por tais práticas sociais, gerou-se uma condição de vida que permitiu que os meios de comunicação fossem penetrando todos os segmentos sociais, através da imprensa e do rádio. Desta forma, as manifestações artístico-culturais foram se desenvolvendo em grande escala e em grande velocidade. Tudo isso contribuiu para o advento da "cultura de massa", que entendemos por uma configuração cultural que engloba grandes populações e que se distingue das culturas particulares dos grupos sociais ou nacionais. A difusão desse tipo de cultura dá-se através dos veículos de comunicação de massa, ou seja, as mídias.

A partir da década de 1920, o termo "indústria cultural" passou a ser utilizado por alguns pensadores alemães para designar um conjunto de mídias que produzissem, transmitissem e lucrassem com o conteúdo artístico-cultural que divulgassem. Esses pensadores se interessavam pelo modo no qual as massas lidavam com o conteúdo exibido e pelo comportamento acrítico diante das grandes campanhas publicitárias. Diante disso, observou-se que os produtos da indústria cultural traziam uma grande particularidade, a saber, o enfraquecimento da arte

\footnotetext{
${ }^{1}$ Walter Benedix Schönflies Benjamin (Berlim, 1892- Portbou 1940) pensador de origem judaica, ensaísta, tradutor, crítico literário, tem sua trajetória intelectual relacionada à Escola de Frankfurt, local onde desenvolver-se a teoria crítica social, focada nas dimensões culturais do modo capitalista de produção. É nessa ambiência que Benjamin traduziu obras de Marcel Proust e Charles Baudelaire, donde a influência para o estudo do vínculo entre a crítica social e a produção artística. Dentre seus principais escritos podemos destacar Teses Sobre o Conceito da História (1940), Paris, capital do século XIX (inacabada), Passagens (compilação de escritos publicados postumamente) e A obra de arte na era de sua reprodutibilidade técnica (1936).
} 
erudita e da arte popular, tendo em vista que ao transformar a cultura em mercadoria, inserida num contexto de grande apelo publicitário fortificado pelas leis da oferta e da procura, o público se tornava passivo, acrítico e sem motivações para buscar novas experiências culturais, pois estavam num ciclo de conformismo com o que estava sendo "apresentado", conhecido e experimentado. A arte passou a ser um reflexo da vontade do consumo, através da mercantilização da cultura.

Nesse sentido, Walter Benjamin escreve em 1936 o ensaio A obra de arte na era de sua reprodutibilidade técnica (Das Kunstwerk im Zeitalter seiner Reproduzierbarkeit) onde aborda que toda obra de arte possui uma "aura", na qual expressa sua singularidade, possuidora de um "o aqui e o agora", revelado por ser uma existência única e autêntica. Entretanto, tais características da obra de arte se diluem mediante os novos meios de reprodutibilidade.

Para melhor desenvolver sua reflexão sobre a arte e a cultura, Benjamin inicia seu ensaio esclarecendo que toda obra de arte sempre foi reprodutível, ou seja, a imitação ora fora feita por alunos para praticarem a arte, ora pelos mestres para divulgarem suas obras, ora, até mesmo, por terceiros que buscavam o lucro. Entretanto, a reprodução técnica da obra de arte é algo que se impôs na história e tem sua crescente intensidade.

O autor faz um retrospecto e nos mostra quais os tipos de reprodução técnica ao longo da história. Cita a fundição, a cunhagem, a xilogravura, a impressão, gravura, litografia. A esta última, o autor confere um caráter de avanço decisivo, visto que é o processo que permitiu colocar os produtos das artes gráficas no mercado não somente em produção em massa, mas também sob formas diversificadas no dia a dia. Entretanto, tempos depois as artes gráficas, aponta o autor, foram ultrapassadas pela fotografia e explica:

Pela primeira vez, com a fotografia, a mão liberta-se das mais importantes obrigações artísticas no processo de reprodução de imagens, as quais, a partir de então, passam a caber unicamente ao olho que espreita por uma objectiva. $^{2}$

Tal consideração leva à reflexão de que através da fotografia observa-se a maior rapidez na reprodução, visto que o "olho apreende mais depressa que a mão

\footnotetext{
2 BENJAMIN, ponto I.
} 
que desenha". Com a ampla reprodução inserida através da fotografia, o autor reflete sobre o recuo do "valor de culto" e o crescimento do "valor de exposição", ou seja, as técnicas de reprodução permitiram o surgimento de uma necessidade cada vez mais crescente de que obras de arte se tornassem mais disponíveis para exposição, logo para estarem inseridas num processo de mercantilização, as tornando meros produtos e mercadorias. É também a partir disso que podemos observar a transformação do valor da obra de arte. Nesse sentido, o autor aponta:

No início do século $X X$, a reprodução técnica tinha atingido um nível tal que começara a tornar objeto seu, não só a totalidade das obras de arte provenientes de épocas anteriores, e a submeter os seus efeitos às modificações mais profundas, como também a conquistar o seu próprio lugar entre os procedimentos artísticos. ${ }^{3}$

Para isso, o autor mostra que as manifestações que comprovam de maneira elucidativa essa afirmativa são a reprodução da obra de arte e do cinema. Muito embora a reprodução possa vir a ser de maneira perfeita, faltará o que Benjamin denomina de "o aqui e o agora da obra de arte". O "aqui e agora" se constitui como a existência única no lugar em que se encontra, e somente nessa existência é que se cumpre a história à qual esteve submetida. Nessa história há dois tipos de modificações: as da estrutura física e as diferentes relações de propriedade.

O "aqui e agora" da obra de arte nos revela o caráter de sua singularidade, visto que não se pode reproduzir a autenticidade. E é justamente esse caráter que veio a se perder com as grandes técnicas de reprodutibilidade. Entretanto, Benjamin faz uma ressalva no tocante ao autêntico: enquanto este mantém sua autoridade total à sua reprodução manual, isto não se sucede relativamente à reprodução técnica, por dois motivos, a saber: em relação ao original, a reprodução técnica surge com mais autonomia do que com a manual, como exemplo cita a capacidade de captação de que uma lente fotográfica tem em superioridade ao olho humano, e a colocação do original em situações que nem o próprio original consegue atingir, como exemplo uma obra de um coral que foi executada em ar livre ou em um teatro, pode ser ouvida em um quarto através da reprodução pelos meios técnicos disponíveis.

\footnotetext{
${ }^{3}$ BENJAMIN, ponto I.
} 
Entretanto, o autor afirma que independente das situações que se pode levar o resultado da reprodução técnica da obra de arte, há de qualquer forma a desvalorização do seu "aqui e agora". Assim sendo compreendemos que a autenticidade é "a suma de tudo o que desde a origem é nela transmissível, desde a sua duração material ao seu testemunho histórico" ${ }^{4}$. Desta forma, se este testemunho se assenta na duração, na reprodução ele tende a vacilar quando a autenticidade escapa ao homem e também ao testemunho histórico da coisa, assim o que vacila é a autoridade da coisa.

Benjamin, a partir disso, passa a tocar no conceito fundamental da obra de arte, a "aura", a existência única, marcada por sua autenticidade, por seu aqui e agora e por sua originalidade. Para o autor, há uma perda da aura da obra de arte por meio da era da reprodutibilidade. Essa perda é um processo sintomático e ultrapassa o domínio da arte e na caracterização da técnica de reprodução, afirma que "liberta o objeto reproduzido do domínio da tradição", pois ao multiplicar aquilo que é reproduzido, transpõe a ocorrência única para a ocorrência em massa. E na medida em que a reprodução vai ao encontro com quem apreende o reproduzido, este passa a se atualizar uma cada uma de suas situações. Há, portanto, um abalo do reproduzido, da tradição e da renovação da humanidade, e esses três aspectos se ligam com os movimentos de massa, que tem no filme o seu agente mais poderoso. Benjamin também aponta para um significado social dos filmes, há aspectos positivos e negativos, dentre os quais destaca como destrutivo a liquidação do valor da tradição na herança cultural.

Benjamin afirma que além de ser passível de alteração, o modo da percepção sensorial da humanidade, ou o medium em que ocorre, é condicionado naturalmente e historicamente. Para o nosso tempo, é possível compreender que podemos entender a decadência da aura, através das alterações no medium da percepção de que somos contemporâneos, além de também ser possível mostrar as condições sociais da decadência. Faz-se necessário entender que é possível ilustrar o conceito de aura para objetos históricos e para objetos naturais e que através disso, a decadência da aura se assenta em duas circunstâncias que se ligam ao crescimento das massas. Para o autor:

\footnotetext{
${ }^{4}$ BENJAMIN, ponto II.
} 
'aproximar' as coisas espacial e humanamente é atualmente um desejo das massas tão apaixonado como a sua tendência para a superação do caráter único de qualquer realidade, através do registro da sua reprodução"5.

Tal afirmativa reflete o desejo das massas de dominar o objeto o fazendo ficar mais próximo pela cópia ou reprodução.

Em contrapartida a esse desejo, temos o fato de que a singularidade da obra de arte é igualmente relacionada à sua maneira de como se instala no contexto da tradição, esta que por ser algo vivo, é mutável. O que pode transformar uma obra de arte ora num objeto de culto ora em um objeto nefasto, no entanto a singularidade de tal obra não se fez deixar-se ausente.

É interessante perceber que o autor aponta 0 culto como expressão original que integra a obra de arte em seu contexto tradicional. A partir disso, afirma a importância da forma da existência da aura não se desligar de sua função ritual, pois "o valor singular da obra de arte 'autêntica' tem o seu fundamento no ritual em que adquiriu o seu valor de uso original e primeiro"6. E independe da maneira como seja transmitido para permanecer reconhecível, mesmo em formas de culto ou rituais secularizados, todavia, com a secularização da arte, o valor de culto perde seu lugar para a autenticidade.

Benjamin chama a nossa atenção para o fato de que é somente na reprodutibilidade técnica da arte que esta se torna emancipada de sua existência parasitária no ritual, de tal forma que "a obra de arte reproduzida, toma-se cada vez mais a reprodução de uma obra de arte que assenta na reprodutibilidade" ${ }^{7}$. Há a perda também de uma "cópia autêntica", tendo em vista que com a tecnologia da chapa fotográfica torna-se possível a reprodução de inúmeras cópias. Em consoante com a decadência do sentido de autenticidade na reprodução da arte, temos também uma modificação da função social da arte, uma vez que há uma troca de fundamentação: passa do assentamento no ritual, para o assentamento em uma outra praxis, a saber, a política.

Diante disso, Benjamin nos explica sobre as tônicas polares da recepção da arte: o valor de culto e o valor de exposição. É sabido que a produção de uma obra

\footnotetext{
5 BENJAMIN, ponto III.

6 BENJAMIN, ponto IV.

7 BENJAMIN, ponto IV
}

Fabrícia de Castro Abreu - Professora efetiva do Estado do Ceará, Brasileira, residente em Fortaleza - CE, E-mail: fabi.filosofia@gmail.com 
de arte tem seu início por compor-se ao serviço do culto, entretanto, atualmente, parece que o valor do culto requer que a obra de arte permaneça oculta, como as esculturas, estátuas, dentre outras, que permanecem inacessíveis ou restritas a poucos. Todavia, ressalta Benjamin, "com a emancipação de cada uma das práticas da arte, do âmbito ritual, aumentam oportunidades de exposição dos seus produtos" ${ }^{\prime 2}$. Ou seja, o valor de exposição passa a ganhar uma configuração maior dentro da era da reprodutibilidade. Cabe destacar também a facilidade da exposição e sua contextualização: as possibilidades de exposição de uma sinfonia prometiam ser superiores ao de uma missa ou ao de uma observação de esculturas em uma catedral medieval, por exemplo.

Observou-se que com a facilidade de exposição, proporcionada pela diversificação dos métodos de reprodução técnica, houve um desvio quantitativo e qualitativo dos pólos de valor de culto e valor de exposição. Basta observar, segundo o autor, que nos primórdios, pela obra de arte ser carregada quase que em absoluto de valor de culto, passou a ser um instrumento de magia e só posteriormente foi reconhecida como obra de arte, e, ao observar também a contemporaneidade, percebemos que o valor de exposição da obra de arte se configurou como uma composição na qual a função passou a ser artística e que, segundo Benjamin, pode ser que venha a se apresentar para nós como algo acidental. De tal forma que a fotografia e o filme são os exemplos mais próximos que nos permitem refletir e ter acesso ao novo caráter do valor de exposição.

Percebemos com isso, que essas novas configurações se aplicam à nova percepção da interação entre o público, ou a massa, em relação a produção artística. De tal forma que ao observarmos o público que vai a um cinema assistir a um filme, vemos a relação não mais de valor de culto, e até mesmo valor de exposição, mas sim uma relação entre produto e consumidor. Embora seja uma produção cultural, não se percebe mais a singularidade, a aura, o essencial, e sim uma mera reprodução de exibições onde o objetivo está imerso na configuração da relação produto-consumo-lucro.

Os dois principais modos de representações artísticas nas quais Benjamin debruça sua reflexão são a fotografia e o filme. E utilizou o exemplo da fotografia

\footnotetext{
8 BENJAMIN, ponto V.
} 
para afirmar que é nela em que o valor de exposição passa a afastar o valor de culto. Entretanto o valor de culto não cedeu seu espaço sem resistência, tendo em vista que é pelo e no rosto humano que ainda podemos observar o valor de culto da imagem, ainda representando a aura das primeiras fotografias. Entretanto, quando o humano se retira da fotografia temos a sobreposição do valor de exposição sobre o valor de culto. O registro fotográfico passa a registrar indícios, tornam-se provas em um processo histórico, há, portanto, um significado político. Sai de cena a contemplação e entra em cena a indicação.

Ainda que um questionamento sobre o valor artístico da fotografia tivesse vigorado por muito tempo, não se questionou sobre a alteração do caráter global da arte por intermédio da invenção da fotografia, nem posteriormente pelos teóricos do cinema. Benjamin considera que a falta de reflexão sobre tais alterações foram um erro, tendo em vista que ao analisar a estética tradicional ficaria claro a influência desses dois modos de produção artística. Os grandes teóricos do cinema, em seu primórdio, ao atribuírem o filme à arte, atribuíam elementos de culto, entretanto, Werfel afirmou que ao se fazer uma releitura cinematográfica de uma obra literária, por exemplo, estaria se fazendo apenas uma cópia estéril do mundo exterior, assim impedindo o cinema de atingir o império da arte. Benjamin cita ainda a afirmação de Werfel sobre a não apreensão do verdadeiro sentido e possibilidades do cinema que seriam a persuasão e expressão de ambiência do maravilhoso, do sobrenatural.

Além disso, Benjamin retrata sobre os dois tipos de consequências referentes ao desempenho do ator de cinema: pelo desempenho artístico ser apresentado ao público por um equipamento, a atuação não é mostrada em sua totalidade, e pelos processos do cinema se desempenharem a partir de cortes e de posicionamentos de cena, assim a representação do ator é submetida a teste ópticos. A segunda consequência, dada ainda pela representação do ator através de um equipamento, reside no fato de que o público torna-se mero apreciador, sem contato pessoal com o ator e por conseguinte decaindo a capacidade de reação frente à atuação. Percebemos a partir disso uma nova interação entre o público e a produção artística: 
"a identificação do público com o ator só se sucede na medida em que aquele se identifica com o equipamento. Assimila, pois, a sua atitude: testa"9.

Ora, indaga-se sobre a presença da aura nesse tipo de produção cultural, tendo em vista que a relação entre o público e o ator está mediada por uma máquina, diferentemente do teatro em que a aura é captada pela plateia, sem intermédios técnicos. O cinema representa uma das novas interações culturais entre homem e máquina, donde é mais importante a apresentação, ou representação, do ator perante a câmera do que com o público em si ou com outrem. E Benjamin aponta que através do cinema o homem se encontra na situação de atuar em sua totalidade de pessoa viva, porém sem aura, tendo em vista que esta é interligada ao entre o aqui e o agora, portanto não estando presente em uma reprodução copiada, já que no registro cinematográfico a máquina, ou o equipamento, é colocado no lugar do público. Desta forma, não somente a aura do ator desaparece, mas também a aura que envolve o personagem.

O contraste da reprodução técnica do cinema em relação ao teatro é o palco. Prova disto se encontra na identificação do autor com um papel. Ora, se no teatro a identificação se faz presente, no cinema esta possibilidade é recusada. A atuação do ator no cinema é o resultado de várias intervenções de elementos de maquinaria. Através das montagens de cena, há uma descontinuidade temporal em relação à ação real, visto que não necessariamente a ação apresentada no filme revela o tempo de duração da gravação, donde revela mais uma vez a ausência de um "aqui e agora". Além disso, o ator de cinema sabe que está ligado ao público, que constitui um mercado. Dadas as circunstâncias de seu tempo, Benjamin afirmou que esse público é incitado a participar a "consumir" a reprodução cinematográfica através de concepções ilusórias e através também de especulações ambíguas.

Diante disto, Benjamin aponta para uma alteração da relação das massas com a arte. Há um indício a ser apontado: quanto maior for a diminuição do significado social de uma arte, mais as atitudes críticas do público se afastam. Afirma que o convencional é apreciado acriticamente e o que é verdadeiramente novo é criticado com aversão, que a reação do público é condicionada pela audiência em massa. $A$ isso pode se relacionar à crise da pintura em XIX, já que

\footnotetext{
${ }^{9}$ BENJAMIN, ponto VIII.
} 
esta passou a ser observada por uma grande quantidade de pessoas, dirigindo-se assim para uma pretensão da obra de arte se dirigir às massas. É considerada como crise, pois a pintura não é uma arte que dá condições a ser objeto de uma recepção coletiva simultânea.

Benjamin relata que o caracteriza o filme não é somente a forma como o homem se apresenta ao equipamento de registro, mas também considera a forma de reprodução do ambiente. Aponta ainda, de forma previsora, que umas das funções de caráter revolucionário do cinema será a de tornar reconhecíveis como idênticos os aproveitamentos tanto da arte quanto da ciência da fotografia, que até então eram divergentes. Isso devido ao fato de que o cinema "aumenta a compreensão das imposições que regem nossa existência e consegue assegurarnos um campo de ação imenso e insuspeito."10

Sobre a relação entre cinema - arte - massas, Benjamin destaca que houve uma mudança qualitativa em detrimento da quantitativa, ou seja, o número elevado de participantes, provocou uma participação de tipo diferente. Esta participação começou de forma depreciativa, como a comparação de Duhamel de que cinema seria "uma passatempo para a ralé", de forma que não exigisse concentração, nem raciocínio. Tal consideração traz consigo a noção de que as massas procuram diversão e a arte requer recolhimento por parte do observador, esse contraste permite formular que o recolhimento pressupõe um mergulho na obra de arte, já as massas apenas absorvem em si a obra de arte. $\mathrm{O}$ autor cita a arquitetura para falar da sua capacidade de atualização e para fundamentar uma tentativa de compreensão para a relação das massas com a obra de arte. A recepção da arquitetura se dá por dois tipos: tátil e óptica. Já o cinema, faz parte de uma recepção na diversão, rejeitando o valor de culto por dois motivos: pelo fato de provocar no público uma atitude crítica e por tal atitude crítica não englobar, no cinema, a atenção. Benjamin afirma que o público se apresenta como um examinador, todavia distraído.

Por fim, Benjamin ao refletir sobre as massas e os regimes políticos, afirma que o fascismo introduziu uma estetização na vida política e, por conseguinte, a tentativa de estetização culmina em um ponto, a saber, a guerra. Do ponto de vista

\footnotetext{
${ }^{10}$ BENJAMIN, ponto XIII.
} 
da técnica, a guerra permite a mobilização dos meios técnicos mantendo as relações de propriedade. Afirma:

A humanidade que, outrora, com Homero, era um objeto de contemplação para s deuses no Olimpo, é agora objeto de autocontemplação. A sua autoalienação atingiu um grau tal que lhe permite assistir à sua própria destruição, como a um prazer estético de primeiro plano. É isto o que se passa com a estética da política, praticada pelo fascismo. ${ }^{11}$

Em contrapartida, o autor afirma que o comunismo responde ao fascismo com a politização da arte. De um todo, não se pode esperar apenas uma reflexão negativa em relação à arte atual, em seus meios de reprodutibilidade técnica, que culminam numa perda da "aura" da obra de arte, do "aqui e agora", bem como foi explicado no início do artigo. O cinema pode vir a se tornar um instrumento para o indivíduo e para a população como uma nova interação com a obra de arte, através de levantes dos mecanismos sociais.

${ }^{11}$ BENJAMIN, Epílogo.

Fabrícia de Castro Abreu - Professora efetiva do Estado do Ceará, Brasileira, residente em Fortaleza - CE, E-mail: fabi.filosofia@gmail.com 


\section{REFERÊNCIAS}

BENJAMIN, W. A Obra de Arte na Era de Sua Reprodutibilidade Técnica. In. Magia e Técnica, Arte e política. Obras escolhidas I. Trad. Rouanet S. P. São Paulo: Brasiliense, 198SD.

BENJAMIN, W. A Obra de arte na Era de Sua Reprodutibilidade Técnica (Org. e Prefácio - Márcio Seligmann-Silva), Tradução: Gabriel Valladão Silva, 1aㅡ Edição, Porto Alegre, RS: L\&PM, 2013.

BENJAMIN, W. A obra de arte na época de sua reprodutibilidade técnica, Apresentação, Tradução e Notas: Francisco De Ambrosis Pinheiro Machado, $1^{\underline{a}}$ Reimpressão, Porto Alegre, RS: Zouk, 2012.

BUC-MORSS, Susan, Dialética do Olhar, Tradução de Ana Luiza Andrade, Belo Horizonte: Editora UFMG e Chapecó: Editora Universitária Argos, 2012.

CALLADO, Tereza de Castro, Walter Benjamin - A Experiência da origem, Fortaleza: Eduece, 23006

KAMBAS, Chryssoula, "Kunstwerk" in:_Benjamins Begriffe, Herausgegeben von OPITZ, Michael und WIZISLA, Erdmut, Zweiter Band, Erste Auflage, Frankfurt am Main: Suhrkamp Verlag, 2000, pp. 524-551.

ROCHLITZ, Rainer, "A arte a serviço da política" in: 0 desencantamento da arte, Tradução de Maria Helena Ortiz Assumpção, Revisão Técnica de Máricio Seligmann, Bauru, SP: EDUSC, Editora da Universidade do Sagrado Coração, 2003. Pp. 156-244. 